\title{
PHYSICAL PROPERTIES OF SPERMACETI OIL IN THE SPERM WHALE
}

\author{
MALCOLM R. CLARKE \\ The Laboratory, Marine Biological Association, Citadel Hill, Plymouth
}

(Figs. 1-4)

\begin{abstract}
As a basis for an understanding of the buoyancy function of the spermaceti organ of the sperm whale (Physeter macrocephalus L.) this paper deals with the following three physical properties of spermaceti oil: (i) the relationship between its density, temperature and pressure; (ii) heat exchange during freezing and melting; and (iii) the elevation of its temperature during increase in pressure.
\end{abstract}

\section{INTRODUCTION}

This is the second of three papers describing the structure, properties and buoyancy function of the spermaceti organ of the sperm whale (Physeter macrocephalus Linnaeus 1758). The first paper (Clarke, 1978a) described the detailed structure and proportions of the spermaceti organ and related structures and considered relevant details of the blubber, skin and lungs. Here, three thermal properties of the spermaceti oil are described which are relevant to a study of the function of the oil. Finally, in a third paper (Clarke, $1978 b$ ) it will be shown that, over its great geographical and depth ranges, the whale varies considerably in buoyancy due to variations in water density and the volume of air in its lungs and it is suggested that, during dives, the whale can control its own density by changing the temperature of the spermaceti oil of the head and may attain neutral buoyancy in dives deeper than $200 \mathrm{~m}$.

\section{METHODS}

Spermaceti oil was collected from the head of sperm whales flensed at the Union Whaling Station, Durban, South Africa. Unless stated to the contrary below, samples were immediately deep frozen under nitrogen and stored in this state until the particular experiment was carried out.

\section{RESULTS}

\section{Density change of spermaceti oil}

As both pressure and temperature affect the density of an oil, it was necessary to examine the three parameters at the same time. At my request, Dr D. Ambrose of the Division of Chemical Standards, National Physical Laboratory, Teddington, measured the fluid compressibility of a spermaceti sample removed from the spermaceti sac of a sperm whale (Beattie, 1934; Douslin et al. 1958). Dr Ambrose's report is as follows and includes Table 1 and Fig. 1.

'The sample of spermaceti was received in a refrigerated condition $\left(-78^{\circ} \mathrm{C}\right)$, and was 


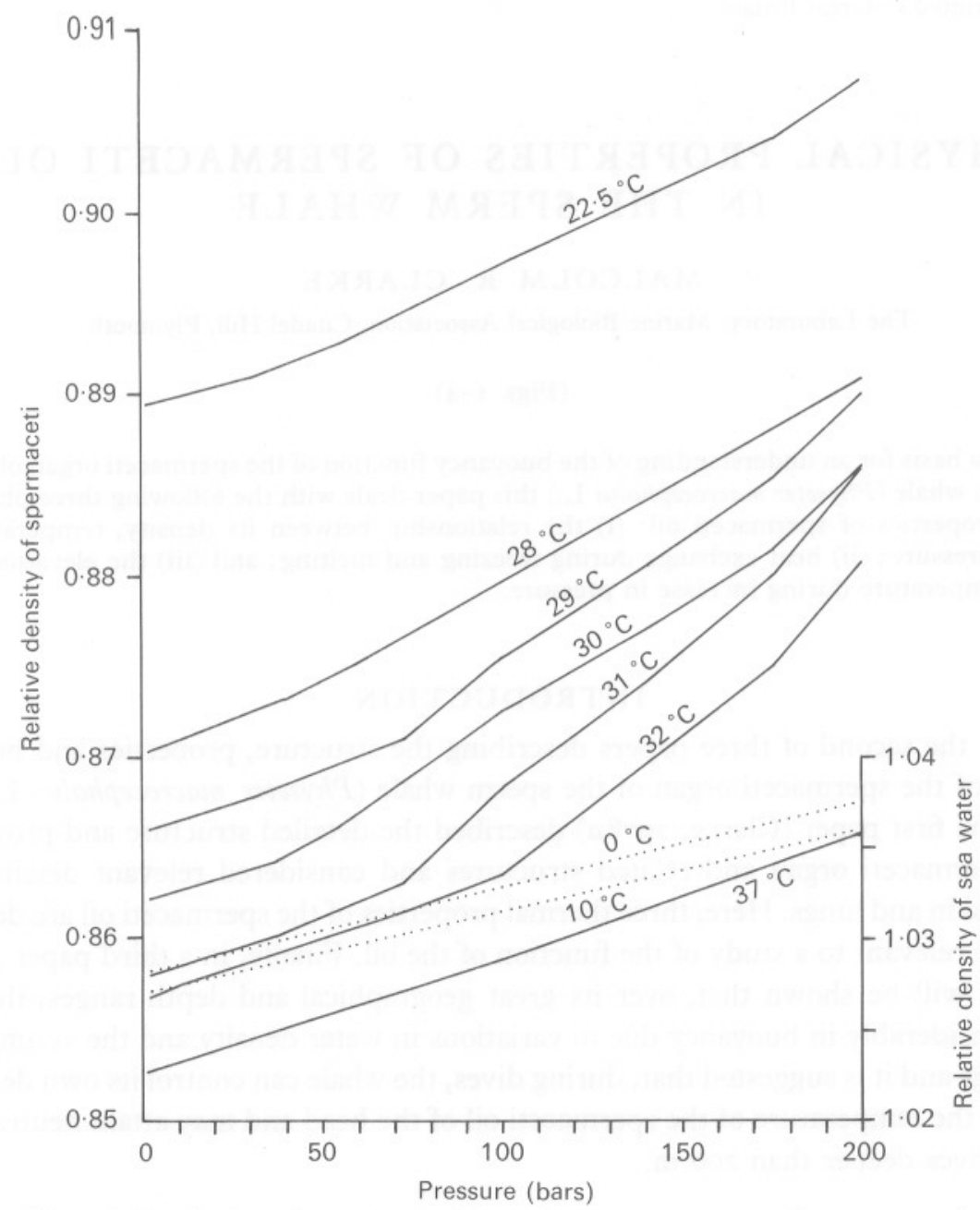

Fig. 1. The relative density of spermaceti oil at various temperatures and pressures. 1 bar $\bumpeq_{1}$ atmosphere. Measurements made at the National Physical Laboratory, England. The right-hand scale relates to the relative density of sea water at 0 and $10^{\circ} \mathrm{C}$ shown as dotted lines.

so maintained until it was required for the measurements. One portion was used for density determination in the apparatus described by Hales (1970) and the following values were obtained:

$$
\begin{aligned}
& \begin{array}{l}
30^{\circ} \mathrm{C} 857 \cdot 3 \mathrm{~kg} / \mathrm{m}^{3} \\
37^{\circ} \mathrm{C} 852 \cdot 6^{\star} \mathrm{kg} / \mathrm{m}^{3}
\end{array} \text { in degassed condition } \\
& \begin{array}{ll}
30^{\circ} \mathrm{C} 857 \cdot 5 & \mathrm{~kg} / \mathrm{m}^{3} \\
37^{\circ} \mathrm{C} 852 \cdot 7 & \mathrm{~kg} / \mathrm{m}^{3}
\end{array} \text { in air-saturated condition } \\
& 40{ }^{\circ} \mathrm{C} 850 \cdot 7 \mathrm{~kg} / \mathrm{m}^{3}
\end{aligned}
$$

When the values at $30^{\circ} \mathrm{C}$ were obtained, some solid was present in the liquid. Another portion of the sample was charged into the apparatus, similar to that described by Beattie (1934), with which its variation in volume with change in temperature and 
pressure could be determined; the volume occupied by the weighed portion of spermaceti at the start of the measurements was calculated from the value of the density given above which is marked with an asterisk.'

The results of these measurements are given in Table 1 . From this table the density of the spermaceti oil at any depth or temperature can be determined.

Table 1. Density $\left(\mathrm{kg} \mathrm{m}^{-3}\right)$ of spermaceti oil $\left(\mathrm{kg} / \mathrm{m}^{3}\right)$ at selected pressures and temperatures

1 atmosphere $=1.013$ bars.

\begin{tabular}{|c|c|c|c|c|c|c|c|c|c|}
\hline \multirow{2}{*}{$\begin{array}{l}\text { Pressure } \\
\text { bar }\end{array}$} & \multicolumn{9}{|c|}{ Temperature $\left({ }^{\circ} \mathrm{C}\right)$} \\
\hline & 0.00 & $15 \cdot 00$ & $22 \cdot 50$ & 28.00 & $29 \cdot 00$ & $30 \cdot 00$ & $31 \cdot 00$ & $32 \cdot 00$ & 37.00 \\
\hline 2.051 & 925.3 & $905 \cdot 3$ & 889.5 & $870 \cdot 3$ & $866 \cdot 0$ & $862 \cdot 2$ & $858 \cdot 0$ & $856 \cdot 9$ & $852 \cdot 6$ \\
\hline 3.613 & 925.3 & 905.5 & $889 \cdot 6$ & $870 \cdot 4$ & $866 \cdot 0$ & $862 \cdot 2$ & $858 \cdot 0$ & 856.9 & $852 \cdot 6$ \\
\hline $10 \cdot 51$ & 925.6 & 905.8 & $890 \cdot 0$ & $870 \cdot 9$ & $866 \cdot 5$ & $862 \cdot 6$ & 858.5 & 857.5 & 853.2 \\
\hline $17 \cdot 40$ & 925.9 & $906 \cdot 2$ & $890 \cdot 3$ & 871.4 & 866.9 & 863.0 & - & - & 853.7 \\
\hline $24 \cdot 30$ & $926 \cdot 2$ & $906 \cdot 6$ & $890 \cdot 6$ & $871 \cdot 9$ & $867 \cdot 4$ & 863.4 & $859 \cdot 4$ & $858 \cdot 4$ & $854 \cdot 2$ \\
\hline 31.19 & $926 \cdot 6$ & $906 \cdot 9$ & $891 \cdot 0$ & $872 \cdot 4$ & $867 \cdot 8$ & 863.8 & - & - & $854 \cdot 6$ \\
\hline 38.09 & $926 \cdot 9$ & $907 \cdot 3$ & $891 \cdot 6$ & 873.0 & $868 \cdot 3$ & $864 \cdot 3$ & $860 \cdot 2$ & $859^{\cdot} \cdot 2$ & $855^{\circ} 0$ \\
\hline $55 \cdot 32$ & 928.0 & 908.5 & $892 \cdot 8$ & $874 \cdot 6$ & $869 \cdot 8$ & $866 \cdot 3$ & - & - & $856 \cdot 2$ \\
\hline $72 \cdot 56$ & 928.8 & $909 \cdot 6$ & 894.5 & $876 \cdot 8$ & $871 \cdot 0$ & 868.4 & 863.0 & $861 \cdot 4$ & $857 \cdot 3$ \\
\hline $107 \cdot 0$ & $930 \cdot 7$ & $911 \cdot 8$ & 897.5 & $880 \cdot 6$ & $875 \cdot 6$ & $872 \cdot 6$ & $868 \cdot 5$ & $863 \cdot 6$ & 859.4 \\
\hline $141 \cdot 5$ & $932 \cdot 7$ & $914 \cdot 3$ & 900.8 & $884 \cdot 4$ & $880 \cdot 6$ & $877^{\circ} 0$ & $874 \cdot 3$ & $869 \cdot 6$ & $861 \cdot 7$ \\
\hline $176 \cdot 0$ & $934 \cdot 7$ & $917 \cdot 0$ & $904 \cdot 1$ & $888 \cdot 1$ & $885 \cdot 5$ & $881 \cdot 5$ & $880 \cdot 1$ & $875 \cdot 0$ & $864^{\circ} \circ$ \\
\hline 210.5 & 936.8 & 919.7 & $907 \cdot 4$ & $891 \cdot 8$ & $890 \cdot 2$ & $886 \cdot 2$ & $886 \cdot 0$ & $880 \cdot 8$ & 866.5 \\
\hline Date of run & $20 / 6$ & $19 / 6$ & $19 / 6$ & $16 / 6$ & $16 / 6$ & $16 / 6$ & $26 / 6$ & $27 / 6$ & $15 / 6$ \\
\hline
\end{tabular}

\section{Heat exchange of the spermaceti oil}

It is also necessary to establish the amount of heat which would have to be removed from the spermaceti oil if its temperature were to drop the required amount to balance the lift at each depth.

Spermaceti oil is a complex mixture of wax esters and triglycerides (Morris, 1975), which is a clear straw-coloured liquid above $30^{\circ} \mathrm{C}$ but becomes cloudy if lowered below that temperature and progressively crystallizes and sets as the temperature drops. Rough measurements made by dipping a thermometer into the oil which poured from the spermaceti organ of six female whales (33-35 ft long; 10-10.7 m) cut up at Durban showed that after the thermometer was withdrawn the cloudiness hid the bulb of the thermometer at $28.5-29 \cdot 7^{\circ} \mathrm{C}$. Half a degree lower the wax seemed solid and half a degree higher it was clear. In fact, observation of larger quantities shows that setting or freezing is a progressive process which continues down to below $0{ }^{\circ} \mathrm{C}$. As with freezing of water, latent heat must be exchanged during freezing or melting, but unlike water, this is lost progressively over a large range of temperature.

The heat exchanged during cooling and heating of spermaceti oil was measured on a Perkin-Elmer differential scanning calorimeter. A first trial was carried out on spermaceti oil which had been collected in August 1969 and stored in air without refrigeration until May 1970. Mr M. R. Cottrell of Perkin-Elmer Ltd very kindly ran this through the model DSC $1 \mathrm{~B}$, and from the heating and cooling thermograms showed that there are 
two peaks of heat exchange and found by planimetry that the peak with a maximum near $30{ }^{\circ} \mathrm{C}$ showed that the oil needed $12.77 \mathrm{cal} / \mathrm{g}$ to raise its temperature from 8 to $38{ }^{\circ} \mathrm{C}$. As this trial with unrefrigerated oil proved hopeful, six more samples of spermaceti oil were kindly collected by Dr R. Gambell from selected positions in the sac and junk of whales
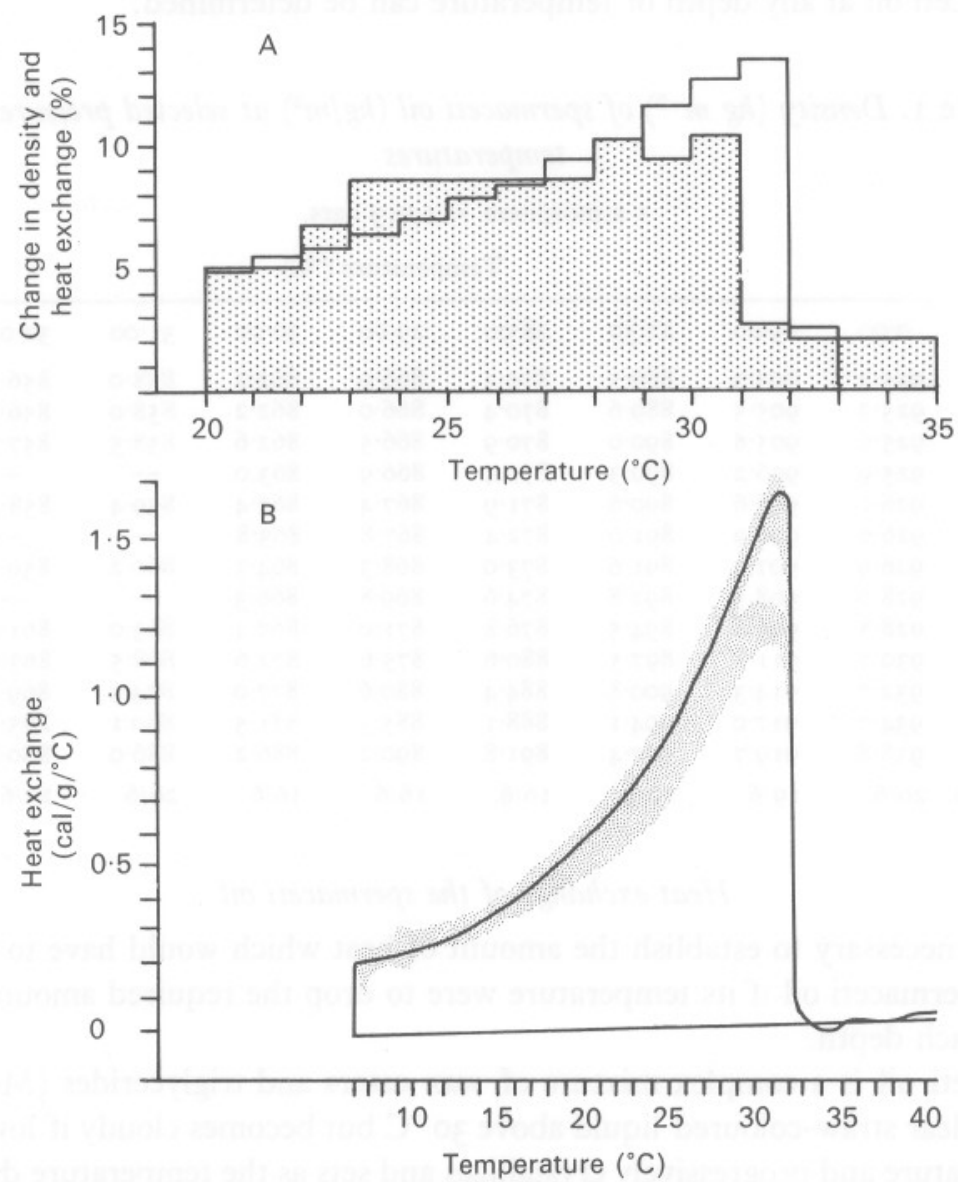

Fig. 2(A) The shaded histogram shows the decrease in density for each degree centigrade, expressed as a percentage of the total decrease in density, if the temperature of naturally occurring spermaceti oil is elevated from 20 to $35^{\circ} \mathrm{C}$. Superimposed on this is a histogram showing the exchange of heat expressed as a percentage per degree centigrade of the total heat exchanged when the oil temperature is elevated from 20 to $35^{\circ} \mathrm{C}$.

(B) The heating traces of naturally occurring spermaceti oil obtained with a differential scanning calorimeter upon which the unshaded histogram in Fig. 2(A) is based. The shaded area includes two traces of all samples given in Table 2. The two samples from the junk had rather lower peaks than the four from the sac. An 'averaged' line for the sac traces is shown and was used to derive the unshaded histogram in Fig. 2(A). The traces were obtained with a scanning rate of $8{ }^{\circ} \mathrm{C} / \mathrm{min}, 3 \mathrm{~cm} / \mathrm{min}$ with an air reference slope of 400 .

examined at Durban and were returned to the United Kingdom in deep freeze under nitrogen. Parts of these were subsequently chemically analysed by Dr R. Morris (Morris, 1975) and he kindly gave me aliquots of the samples. By arrangement with Dr A. J. Collings, Dr Reid of Unilever Research Laboratory, Bedford, then used another 
Perkin-Elmer DSC to obtain three heating and one cooling trace for each sample. The conditions used were Range 8 heating rate $8{ }^{\circ} \mathrm{C} \mathrm{min}-1$, chart speed $3 \mathrm{~cm} \mathrm{~min}^{-1}$, and the calibration factor used under these conditions is $1 \mathrm{~cm}^{2}=4.164 \mathrm{~m}$ cal. The recorder was run at $5 \mathrm{mV}$ full-scale deflexion. The second and third heating traces obtained were measured using a planimeter to give the calorific exchange (Table 2). This shows that there is little difference between the samples, which is borne out by the traces of heating curves when superimposed (Fig. 2B).

Table 2. Spermaceti oil: calorific exchange during heating (see text for explanation)

$\begin{array}{lccccc}\text { Sample } & \begin{array}{c}\text { Weight } \\ (\mathrm{mg})\end{array} & \begin{array}{c}\text { Area } \\ \left(\mathrm{cm}^{2}\right), \\ \text { trace 1 }\end{array} & \begin{array}{c}\text { Area } \\ \left(\mathrm{cm}^{2}\right), \\ \text { trace 2 }\end{array} & \begin{array}{c}\text { Area } \\ (\mathrm{cal} / \mathrm{g}), \\ \text { trace 1 }\end{array} & \begin{array}{c}\text { Area } \\ (\mathrm{cal} / \mathrm{g}),\end{array} \\ \text { trace 2 }\end{array}$

Trace 2 of the sample sac waxes $\mathrm{B}$ upper was measured up in certain sections:

$\begin{array}{ccccccc} & 0-40{ }^{\circ} \mathrm{C} & 38-33{ }^{\circ} \mathrm{C} & 33-31{ }^{\circ} \mathrm{C} & 31-29^{\circ} \mathrm{C} & 29-27{ }^{\circ} \mathrm{C} & 25-8{ }^{\circ} \mathrm{C} \\ \mathrm{cal} / \mathrm{g} & 18.647 & 0.040 & 1.571 & 3.021 & 3.021 & 7.692\end{array}$

Table 3. Exchange of calories required to cool or heat the spermaceti oil between degrees Centigrade in the range $20-33^{\circ} \mathrm{C}$.

Derived from a mean curve of 6 samples.

$\begin{array}{clc}\begin{array}{c}\text { Temperature } \\ \left({ }^{\circ} \mathrm{C}\right)\end{array} & \mathrm{cal} / \mathrm{g} & \begin{array}{c}\mathrm{cal} / \mathrm{g} \\ \text { cumulative }\end{array} \\ >32 & 0.3 & 0.3 \\ 31 & 1.612 & 1.912 \\ 30 & 1.513 & 3.425 \\ 29 & 1.384 & 4.809 \\ 28 & 1.225 & 6.034 \\ 27 & 1.131 & 7.165 \\ 26 & 1.023 & 8.188 \\ 25 & 0.933 & 9.121 \\ 24 & 0.843 & 9.964 \\ 23 & 0.770 & 10.734 \\ 22 & 0.701 & 11.435 \\ 21 & 0.658 & 12.093 \\ 20 & 0.589 & 12.682\end{array}$

Trace 2 of the sample taken from the upper sac B was measured up in sections and the calorific exchange for each section is shown in Table 2.

By dividing the energy exchange curve into $1{ }^{\circ} \mathrm{C}$ sections the calories per gram exchanged for each degree at atmospheric pressure can be determined (Table 3 , column 2). The total calories per gram which must be lost if the temperature is dropped from $33{ }^{\circ} \mathrm{C}$ (the oil's temperature in the whale - see Clarke, 1978b) to any temperature is shown in Table 3 , column 3. 
Because of the lag in the instrument, the shape of the peak is likely to be slightly distorted since the temperature scale is only accurate to a degree or so.

The maximum for the exchange of heat would be expected to be at the same temperature as the maximum change in density. From the measurements, however, the peaks do not exactly coincide, the greatest change in energy exchange appears to take place at $32{ }^{\circ} \mathrm{C}$ while the greatest change in density takes place at $31{ }^{\circ} \mathrm{C}($ Fig. $2 \mathrm{~A})$. As the energy

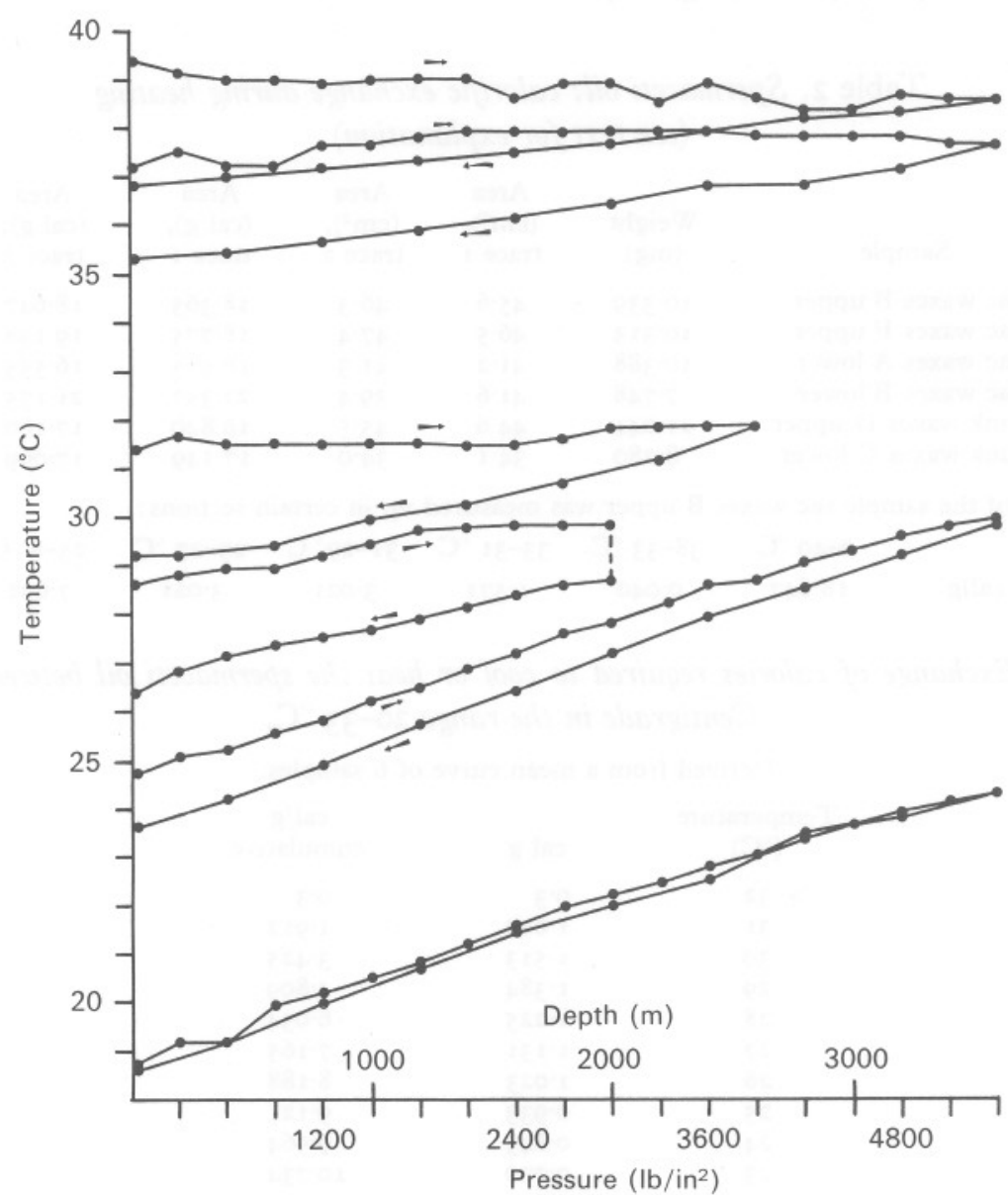

Fig. 3. Measurements of the temperature of spermaceti oil subjected to pressure in a pressure chamber. Arrows indicate whether the pressure was rising or falling.

exchange is based upon heating curves, this is probably due to the lag in the instrument and $31{ }^{\circ} \mathrm{C}$ is likely to be the temperature at which both the greatest change in density and the greatest change in energy exchange occurs.

When considering energy exchange at different temperatures it is therefore necessary to correct for this lag (Clarke, 1978b). 


\section{Rise in temperature of oil with pressure}

As pressure is applied to oils their temperature rises slightly prior to loss of heat to the environment. Experiments were carried out to ascertain the increase in temperature when 1 litre of spermaceti oil was compressed in a polythene bag at several different temperatures. The sample was warmed to above the temperature required and placed in water within the pressure chamber. Temperature of the oil was measured with a calibrated thermistor which was not sensitive to pressure changes, placed approximately in the centre of the oil. When the oil had dropped to the desired temperature, pressure was applied by pumping and the temperature of the oil was read at regular intervals of

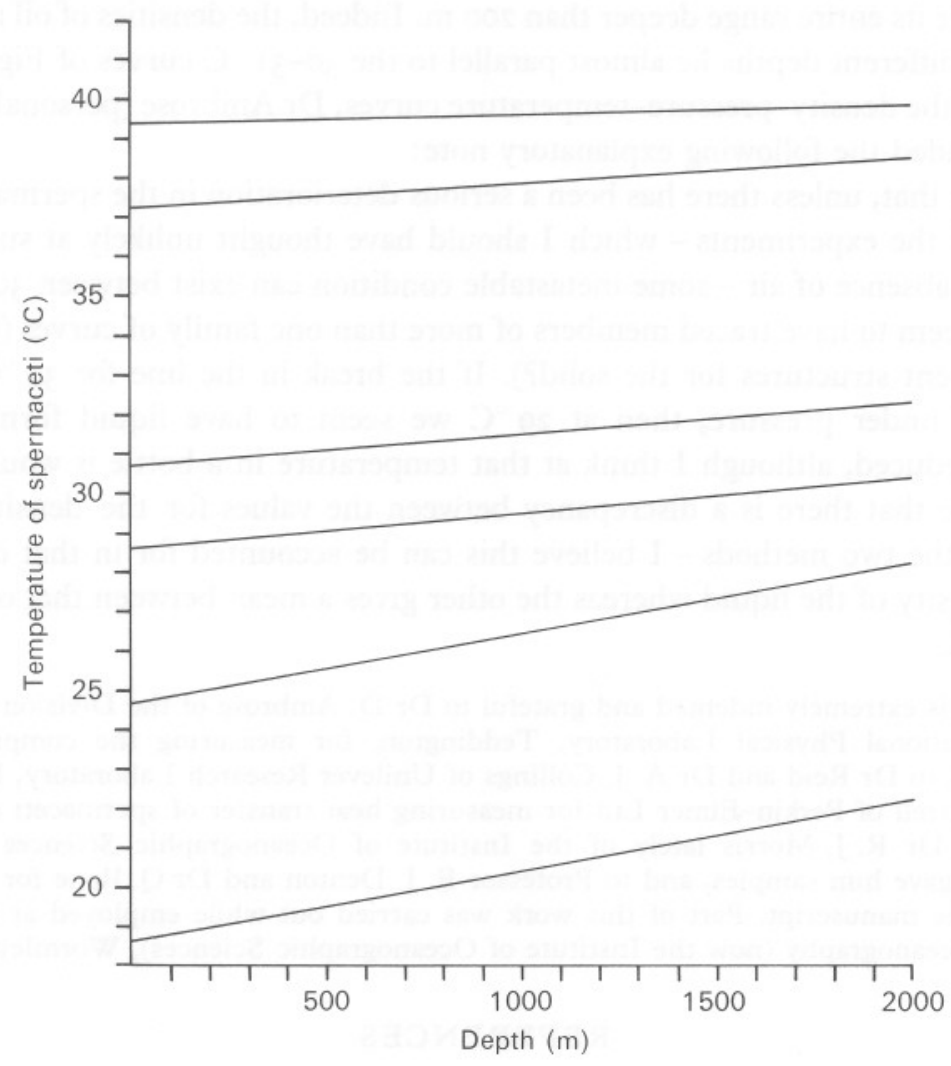

Fig. 4. Lines showing increase in temperature of spermaceti oil with increase in pressure. Derived from the measurements in Fig. 3 by removing the effect of loss of heat from the oil to the water in the pressure chamber.

pressure (as in Fig. 3). Pauses at each pressure were kept as brief as possible. The pressure chamber was full of water at a lower temperature than the oil in all but one experiment. Consequently, heat was lost from the oil during experiments with starting temperatures over $20^{\circ} \mathrm{C}$ (Fig. 3). The difference between the starting temperature and the final temperature at atmospheric pressure gave the average rate of cooling and this was used to correct the curve as pressure was increasing so as to give an approximate 
measure of the increase in temperature with increase in pressure at several temperatures (Fig. 4). From this it is clear that the spermaceti does not behave in an unusual way when compared with other oils. The rise in temperature is greater, the lower the initial temperature, particularly when the oil is partly frozen (below $31^{\circ} \mathrm{C}$ ).

\section{DISCUSSION}

In the paper dealing with the buoyancy control function of the spermaceti organ (Clarke, 1978b) it is shown that the whale only needs to drop the temperature of the spermaceti oil about $3{ }^{\circ} \mathrm{C}$ to achieve the change in density necessary to obtain neutral buoyancy over its entire range deeper than $200 \mathrm{~m}$. Indeed, the densities of oil required by the whale at different depths lie almost parallel to the $30-31{ }^{\circ} \mathrm{C}$ curves of Fig. 1.

Regarding the density-pressure-temperature curves, Dr Ambrose (personal communication) appended the following explanatory note:

'It appears that, unless there has been a serious deterioration in the spermaceti during the course of the experiments - which I should have thought unlikely at such temperatures in the absence of air - some metastable condition can exist between 30 and $32{ }^{\circ} \mathrm{C}$ because we seem to have traced members of more than one family of curves (could there be two different structures for the solid?). If the break in the line for $32{ }^{\circ} \mathrm{C}$ indicates solidification under pressure, then at $29^{\circ} \mathrm{C}$ we seem to have liquid forming as the pressure is reduced, although I think at that temperature in a bottle it would be solid. You will note that there is a discrepancy between the values for the density at $30^{\circ} \mathrm{C}$ obtained by the two methods - I believe this can be accounted for in that one method gives the density of the liquid whereas the other gives a mean between that of the liquid and the solid.'

The author is extremely indebted and grateful to Dr D. Ambrose of the Division of Chemical Standards, National Physical Laboratory, Teddington, for measuring the compressibility of spermaceti oil, to Dr Reid and Dr A. J. Collings of Unilever Research Laboratory, Bedford, and Mr M. R. Cottrell of Perkin-Elmer Ltd for measuring heat transfer of spermaceti oil, to Dr R. Gambell and Dr R. J. Morris lately of the Institute of Oceanographic Sciences who kindly collected and gave him samples, and to Professor E. J. Denton and Dr Q. Bone for very helpful criticism of the manuscript. Part of this work was carried out while employed at the National Institute of Oceanography (now the Institute of Oceanographic Sciences), Wormley, Surrey.

\section{REFERENCES}

Beattie, J. A., 1934. The apparatus and method used for the measurement of the compressibility of several gases in the range of $0^{\circ}$ to $325^{\circ}$ C. Proceedings of the American Academy of Arts and Sciences, 69, 389-405.

ClaRKe, M. R., 1978 a. Structure and proportions of the spermaceti organ of the sperm whale. Fournal of the Marine Biological Association of the United Kingdom, 58, 1-17.

Clarke, M. R., 1978b. Buoyancy control as a function of the spermaceti organ of the sperm whale. Fournal of the Marine Biological Association of the United Kingdom, 58, 27-71.

Douslin, D. R., Moore, R. T., Dawson, J. P. \& Waddington, G., 1958. The pressure-volumetemperature properties of fluorobenzene. Fournal of the American Chemical Society, 80, 2031-2038.

HALES, J. L., 1970. An apparatus for accurate measurement of lipid densities over an extended temperature range. Fournal of Physics (E: Scientific Instruments), 3, 855-861.

MorRIS, R. J., 1975. The lipid structure of the spermaceti organ of the sperm whale (Physeter catodon). Deep-Sea Research, 20, 911-916. 